\title{
Effects of Microcin B17 on Microcin B17-immune Cells
}

\author{
By MARTA HERRERO, ${ }^{1}+$ ROBERTO KOLTER ${ }^{2}$ AND FELIPE MORENO ${ }^{1 *}$ \\ 'Unidad de Genética Molecular, Servicio de Microbiologia, Hospital Ramón y Cajal, \\ Carretera de Colmenar, Km 9,100, Madrid 28034, Spain \\ 2Department of Microbiology and Molecular Genetics, Harvard Medical School, Boston, \\ Massachusetts 02115, USA
}

(Received 14 June 1985; revised 30 August 1985)

\begin{abstract}
When microcin B17-immune cells are treated with microcin B17 they show many of the physiological effects displayed by microcin B17-sensitive cells treated in the same way. DNA replication stops immediately and several SOS functions are subsequently induced. In sensitive cells these effects are irreversible and lead to cell death, whereas in immune cells they are reversible and there is no loss of viability. This is an unusual mechanism of immunity because it does not prevent the primary action of the microcin. The implications of this mechanism concerning the mode of action of microcin B17 and the induction of the SOS system are discussed.
\end{abstract}

\section{INTRODUCTION}

Microcin B17 is a low-molecular-weight antibiotic peptide produced by Escherichia coli strains carrying the $70 \mathrm{~kb}$ plasmid pMccB17, previously referred to as pRYC17 (Baquero et al., 1978; Hernández-Chico et al., 1982). This plasmid also encodes immunity to microcin B17, thus ensuring that producer strains are protected against the killing effect of the anti-bacterial agent.

Microcin B17 kills sensitive $E$. coli $\mathrm{K} 12$ cells. Its primary effect is the inhibition of DNA synthesis. DNA degradation follows and expression of the SOS repair system is induced. This induction depends on the bacterial products $\operatorname{Rec} A$ and $R e c B C$ and requires the presence of an active chromosome replication fork in the treated cells (Herrero \& Moreno, 1986). Whatever the target of the microcin, the antibiotic seems to inactivate, irreversibly, the active replication complexes of sensitive cells.

As with colicins (Konisky, 1982), microcin immunity is a general property of microcinogenic cells (Baquero \& Moreno, 1984). Immunity is specific for each bacteriocin (colicin or microcin) and it protects against both endogenous (that synthesized by the cells) and exogenous microcin. The molecular and physiological basis for immunity to colicins has been extensively studied for several colicins (Jakes, 1982; Konisky, 1982). Briefly, immunity to a colicin is mediated by a protein specific for the colicin and is encoded by the plasmid that encodes the cognate colicin. For colicins with cytoplasmic targets (E2, E3 and DF13), the immunity protein interacts with the colicins, masking their catalytic site (Konisky, 1982). It is thought that channel-forming colicins (E1, Ia and Ib) interact with their immunity protein in the cytoplasmic membrane (Weaver et al., 1981). In both cases, these interactions prevent the action of colicins on their targets.

In contrast, the results presented here indicate that immunity to microcin does not prevent this antibiotic from exerting its primary effect. Indeed, microcin B17 has similar physiological effects in sensitive and immune cells but immune cells are not killed. This represents a novel

$\dagger$ Present address: Department of Microbiology and Molecular Genetics, Harvard Medical School, Boston, MA 02115 , USA. 
mechanism of immunity and the implications concerning the mode of action of microcin B17 and induction of the SOS repair system are discussed.

\section{METHODS}

Bacteria and plasmids. The strains of $E$. coli used are listed in Table 1. Plasmid pColE2-P9 determines synthesis of colicin E2 and immunity to this colicin (Mock \& Pugsley, 1982). Plasmids pMM833 $\left(\mathrm{Mcc}^{+} \mathrm{Imm}^{+}\right) \mathrm{and}^{-}$ pMM827 $\left(\mathrm{Mcc}^{-} \mathrm{Imm}^{+}\right)$are two derivatives of the low copy number wild-type plasmid pMccB17 obtained by insertion of Tn5 (San Millán et al., 1985b). Multicopy plasmids pMM102 ( $\left.\mathrm{Mcc}^{+} \mathrm{Imm}^{+}\right)$, pMM120 $\left(\mathrm{Mcc}^{-} \mathrm{Imm}^{+}\right)$,

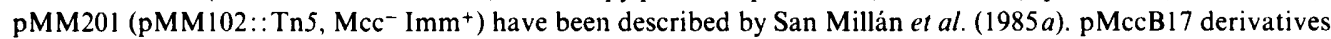
were introduced into strains by conjugation, while pMM102 derivatives were introduced by transformation.

Media and experimental methods. These were all as described in the accompanying paper (Herrero \& Moreno, 1986). Microcin extracts and non-microcin control extracts were prepared from RYC 893 and RYC 895 , respectively, and were assayed on strain BM21. $\beta$-Galactosidase activity was measured, and units were calculated, as described by Miller (1972).

\section{RESULTS}

Microcin B17 inhibits DNA replication in microcin B17-immune cells

During studies on the production of and immunity to microcin B17 we observed that the growth of immune cells was inhibited in the presence of high concentrations of exogenous microcin, but that cell death did not follow. These observations led us to study in detail the behaviour of immune cells in the presence of the antibiotic. To evaluate the effects of exogenous microcin, experiments were done with cells carrying plasmids encoding the immunity function but not microcin synthesis, thus eliminating possible effects of endogenous microcin. We examined cell growth, cell viability, DNA metabolism and expression of the SOS repair system, phenomena known to be affected in sensitive cells treated with microcin B17 (Herrero \& Moreno, 1986).

Table 1. E. coli strains used

\section{Strain}

\begin{tabular}{|c|c|}
\hline BM21 & $\operatorname{GyrA}^{-}\left(\lambda^{+}\right)$ \\
\hline MC4100 & araD139 $\Delta$ lacU169 $\mathrm{RpsL}^{-} \mathrm{RelA}^{-} \mathrm{ThiA}^{-}$ \\
\hline RYC511 & As MC4100, pColE2-P9 \\
\hline RYC384 & As MC4100, pColE2-P9, pMM827 \\
\hline pop3351 & As $\mathrm{MC} 4100, \triangle \mathrm{malBl}$ \\
\hline RYC388 & As pop3351, pMM827 \\
\hline RYC389 & As pop3351, pMM201 \\
\hline RYC893 & As pop3351, pMM102 \\
\hline RYC895 & As pop3351, pMM120 \\
\hline $\mathrm{HfrH}$ & $\mathrm{GalE}^{-}$ \\
\hline RYC379 & As $\mathrm{HfrH}, \mathrm{pMM} 827$ \\
\hline GC4415 & 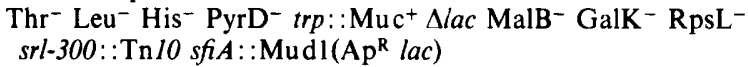 \\
\hline RYC354 & As GC4415, $\Delta($ sbmA-phoA $) 14$ \\
\hline RYC355 & As GC4415, pMM827 \\
\hline RYC356 & As GC4415, pMM833 \\
\hline RYC357 & As GC4415, pMM201 \\
\hline RYC359 & As RYC 354 , pMM 833 \\
\hline RYC361 & As pop3351, Thy ${ }^{-}$ \\
\hline RYC394 & As RYC 361 , pMM 827 \\
\hline RYC382 & 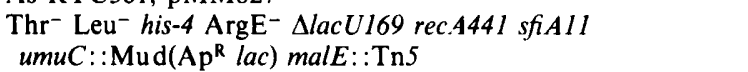 \\
\hline RYC 383 & As RYC382, pMM 827 \\
\hline GC2375 & $\begin{array}{l}\mathrm{Thr}^{-} \mathrm{Leu}^{-} \text {Pro- his-4 argE3 } \mathrm{Thi}^{-} \mathrm{Lac}^{-} \mathrm{Gal}^{-} \mathrm{RpsL}^{-} \text {sup-37 } \\
{[\lambda \mathrm{d}(\text { rec } A:: \text { :lac }) \text { clind }]}\end{array}$ \\
\hline RYC392 & As GC2375, pMM827 \\
\hline GC2421 & As $\mathrm{GC} 2375$, $\operatorname{recB} 21$. \\
\hline RYC393 & As GC2421, pMM 827 \\
\hline
\end{tabular}

Reference or source*

Hernández-Chico et al. (1982)

Casadaban (1976)

Hernández-Chico et al. (1982)

Hernández-Chico et al. (1982)

\}San Millán et al. (1985a)

J. Beckwith

Huisman \& D'Ari (1981)

Herrero \& Moreno (1986)

Herrero \& Moreno (1986)

Casaregola et al. (1982)

Casaregola et al. (1982)

* Strains for which no reference or source is given are described in this paper. Address: J. Beckwith, Harvard Medical School, Boston, USA. 


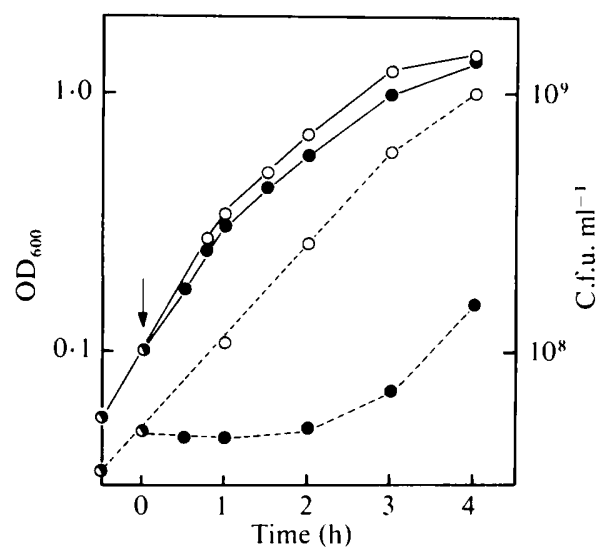

Fig. 1

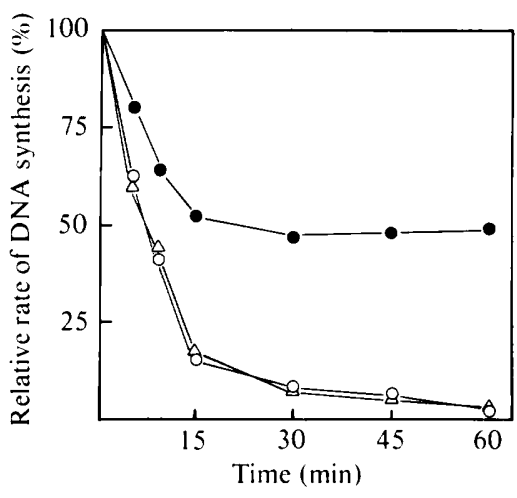

Fig. 2

Fig. 1. Effect of microcin B17 on the growth of immune cells. A culture of GC2375(pMM827), grown exponentially in M63 glucose medium, was split into two subcultures. At time zero, one subculture received microcin ( $200 \mathrm{AU} \mathrm{ml}^{-1}$ ) and the other an equivalent volume of a non-microcin control extract. Incubation was continued and at various times the cell mass was determined spectrophotometrically and the number of c.f.u. was determined by plating on LB medium. $\bigcirc$, Control;, , microcin B17; absorbance: ---- , c.f.u. $\mathrm{ml}^{-1}$.

Fig. 2. Inhibition of the rate of DNA synthesis in microcin B17-immune cells in the presence of microcin B17. Bacterial cultures were grown exponentially in M63 glucose. When cultures reached an $\mathrm{OD}_{600}$ of 0.5 (time zero) each received $200 \mathrm{AU}$ microcin $\mathrm{B} 17 \mathrm{ml}^{-1}$ and incubation was continued for $1 \mathrm{~h}$. At various times, $0.3 \mathrm{ml}$ samples were removed and pulse-labelled with [ $\left.m e t h y l-{ }^{3} \mathrm{H}\right]$ thymidine for $3 \mathrm{~min}$, in the presence of 2-deoxyadenosine $\left(200 \mu \mathrm{g} \mathrm{ml}^{-1}\right)$. The samples were precipitated in $5 \%(\mathrm{w} / \mathrm{v}) \mathrm{TCA}$, filtered and radioactivity on the filters was counted. The rates of incorporation are expressed as a percentage of that of the untreated control: the absolute values in the control were $50000-100000 \mathrm{c} . \mathrm{p} . \mathrm{m}$. $\triangle$, pop3351; O, pop3351(pMM827);, $\operatorname{pop3351(pMM201).~}$

When exponentially growing microcin-sensitive cells were treated with microcin B17 (200 $\mathrm{AU} \mathrm{ml}^{-1}$ ) the bacterial mass continued to increase normally for about $1 \mathrm{~h}$. However, cells immediately lost viability upon antibiotic treatment. Under the same experimental conditions, microcin B17 only slightly affected the growth of immune cells, as measured by the increase in the optical density of the culture, and the number of c.f.u. remained constant for 2-3 h (Fig. 1). Microscopic observation of immune cells $2 \mathrm{~h}$ after addition of the antibiotic indicated that, as with sensitive cells, most had formed filaments. But, whereas cell filaments from sensitive strains were not viable, those from immune strains gave colonies when plated on microcin-free medium.

We have previously shown that the primary effect of microcin B17 on sensitive cells is to inhibit DNA synthesis. This also occurred with immune cells. In fact, the reduction in the rate of synthesis was the same in sensitive pop3351 cells and in immune pop3351(pMM827) cells when they were treated with microcin $\mathrm{B} 17$ at $200 \mathrm{AU} \mathrm{ml}^{-1}$ (Fig. 2). Less inhibition of DNA synthesis was observed when the immune bacteria harboured the multicopy plasmid pMM201, indicating that the extent of inhibition depends on the copy number of the immunity genes.

\section{Microcin B17 induces expression of the SOS system in immune cells}

Agents or culture conditions that damage DNA or interfere with DNA replication induce the SOS response (Little \& Mount, 1982). This response involves the inhibition of cell division and an increased capacity for DNA repair and mutagenesis, and may lead to colicin induction and derepression of a number of prophages. After treatment with an inducing agent, a signal is generated which reversibly activates the RecA protein, which in its active form can cleave the LexA protein, and some phage repressors. The inactivation of the LexA protein allows increased 
Table 2. Induction of SOS gene expression in sensitive and immune cells in the presence of microcin $B 17$

\begin{tabular}{|c|c|c|c|c|c|c|}
\hline \multirow{2}{*}{$\begin{array}{l}\text { Gene } \\
\text { fusion }\end{array}$} & \multirow[b]{2}{*}{ Strain } & \multirow{2}{*}{$\begin{array}{l}\text { Microcin } \\
\left(\mathrm{AU} \mathrm{ml}^{-1}\right)\end{array}$} & \multicolumn{4}{|c|}{$\begin{array}{c}\beta \text {-Galactosidase activity } \\
\text { (Miller units) }\end{array}$} \\
\hline & & & $0 \mathrm{~min}$ & $45 \mathrm{~min}$ & $90 \mathrm{~min}$ & $135 \mathrm{~min}$ \\
\hline \multirow[t]{4}{*}{$\operatorname{rec} A:: \operatorname{lac} Z$} & GC2375 & 150 & 150 & 600 & 1120 & 1390 \\
\hline & & 30 & - & 260 & 700 & 1000 \\
\hline & RYC392 & 150 & 150 & 400 & 970 & 1250 \\
\hline & & 30 & - & 180 & 320 & 440 \\
\hline \multirow[t]{4}{*}{ umuC: :lac Z } & RYC382 & 150 & 7 & 30 & 50 & - \\
\hline & & 30 & - & 25 & 30 & - \\
\hline & RYC383 & 150 & 2 & 7 & 17 & 27 \\
\hline & & 30 & - & 3 & 7 & 12 \\
\hline \multirow[t]{2}{*}{ sfiA::lacZ } & GC4415 & 150 & 26 & 360 & 1070 & 900 \\
\hline & RYC 355 & 150 & 28 & 240 & 1030 & 870 \\
\hline
\end{tabular}

expression of many genes (SOS genes) normally repressed by this protein in uninduced cells. Using operon fusions of $\mathrm{Mudl}\left(\mathrm{Ap}^{\mathrm{R}} l a c\right)$ and $\mathrm{SOS}$ genes $(\operatorname{rec} A, s f A, u m u C)$ we have shown that microcin $\mathrm{B} 17$ induced expression of $\beta$-galactosidase in immune cells as well as in microcinsensitive cells (Table 2). The extent of the induction depended on the microcin concentration. The immunity gene copy number also affected the level of $\beta$-galactosidase activity. For example, after 90 min treatment with $200 \mathrm{AU}$ microcin B17 ml-1 strain RYC355 (single-copy of immunity gene) had 1500 Miller units of $\beta$-galactosidase, while RYC357 (multi-copy immunity) had 500 units.

Colicin production is repressed in colicinogenic strains by the LexA repressor (Pugsley, 1984a). As expected from our findings, microcin B17 derepressed the production of colicin E2 in microcin-immune strains. We found the same increase in the level of colicin E2 (104-fold) when we incubated MC4100(pColE2-P9) or MC4100(pColE2-E9, pMM827) for $100 \mathrm{~min}$ in the presence of $150 \mathrm{AU}$ microcin $\mathrm{ml}^{-1}$.

As in sensitive cells, the microcin B17-induced SOS expression in immune cells also required the RecBC product. No induction of rec $A$-lacZ expressions as observed in GC2421 and RYC393 strains. All of the above results indicated that, when microcin B17 was present at a sufficiently high concentration, the extent of its inhibition of DNA synthesis and induction of SOS functions were practically indistinguishable between sensitive and immune cells. However, whereas sensitive cells were killed, immune cells remained viable.

\section{Differences in the response to microcin B17 in sensitive and immune cells}

First, all of the effects due to the microcin were reversible in immune cells, but not in sensitive cells. For example, immune cells eventually recovered their ability to divide (see Fig. 1). Specifically, when microcin was removed from a culture of pop3351(pMM827) treated for $1 \mathrm{~h}$ with microcin (under conditions like those described in Fig. 2), $1 \mathrm{~h}$ incubation in microcin-free fresh medium was sufficient to recover almost completely the ability to synthesize DNA. The rate of DNA synthesis reached $70 \%$ of the value of the untreated control, whereas DNA synthesis in sensitive cells remained at an undetectable level $(<1 \%)$. The reversibility of microcin B17 action is also illustrated in Fig. 3, where it is apparent that for full induction of $s$ fiA in immune cells, continuous presence of the microcin was required. In contrast, in microcinsensitive bacteria, short treatments with the same amount of microcin were more efficient for sf $A$ induction than long treatments (see Fig. 3). The results obtained with immune strains were similar to those found with nalidixic acid, a reversible inhibitor of DNA gyrase (Sugino et al., 


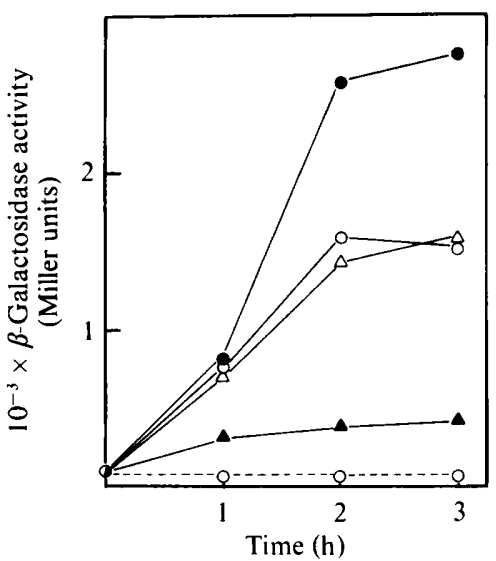

Fig. 3

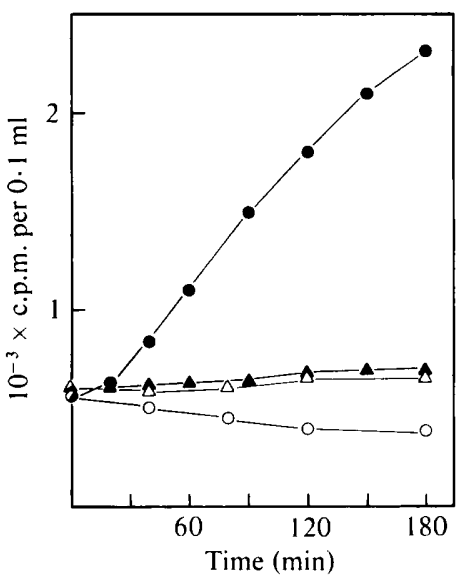

Fig. 4

Fig. 3. Induction of $s f A$ expression with microcin B17 in sensitive and immune cells. Cultures of GC4415 and GC4415(pMM827) grown exponentially in supplemented M63 medium were harvested, washed and resuspended in fresh medium. Microcin B17 (200 $\left.\mathrm{AU} \mathrm{ml}^{-1}\right)$ was added to both cultures. After $5 \mathrm{~min}$ incubation, half of each culture was washed and resuspended in antibiotic-free medium. The remainder of each culture was maintained in the presence of microcin. At various times the $\beta$ galactosidase activity in each culture was determined. GC4415: continuous treatment $(O) ; 5 \mathrm{~min}$ treatment (O). GC4415(pMM827): continuous treatment $(\triangle) ; 5$ min treatment $(\Delta)$. Dashed line: GC4415 and GC4415(pMM827) treated with non-microcin control extract.

Fig. 4. Microcin B17-induced DNA degradation. Exponentially growing cultures of RYC361 and RYC361(pMM827), prelabelled with $\left[\right.$ methyl $\left.-{ }^{3} \mathrm{H}\right]$ thymidine, were washed and then treated with microcin B17 (200 AU ml-1). Duplicate samples of $0.2 \mathrm{ml}$ were taken at various times. TCA-soluble counts are shown for treated $(O)$ and untreated $(O)$ sensitive cells, and treated $(\Delta)$ and untreated $(\triangle)$ immune cells.

1977); the continuous presence of this antibiotic was required to obtain an efficient sfiA induction (Herrero \& Moreno, 1986).

Secondly, microcin B17 is not mutagenic in immune cells. Mutagenesis by UV and many chemicals is an inducible SOS function (Witkin, 1976). The enhancement of the spontaneous mutation frequency requires the products of the $u m u C$ and $u m u D$ genes, which form an operon repressed by the LexA product (Bagg et al., 1981; Shinagawa et al., 1983; Walker, 1984). In microcin-sensitive bacteria $u m u C$ induction was accompanied by an increase in the mutation rate of the lac and gal operons which was dose-dependent (Herrero \& Moreno, 1986). In contrast, treatment of strain $\mathrm{HfrH} \mathrm{GalE}^{-}$harbouring pMM827, in conditions in which umuC was efficiently expressed $\left(1 \mathrm{~h}\right.$ with $\left.200 \mathrm{AU} \mathrm{ml}^{-1}\right)$, failed to increase the mutation rate in these operons.

Thirdly, no significant DNA degradation was observed in immune cells, whereas the DNA of sensitive cells was extensively degraded in the presence of antibiotic (Fig. 4). Thus, immunity does not prevent the inhibition of DNA replication but does protect DNA from the degradation which follows inhibition of DNA replication.

The sfiA-lacZ fusion is expressed constitutively at low level in cells producing microcin B17

Exogenous microcin induces the SOS system in sensitive and immune cells. Hence, the expression of this system in cells producing microcin was also investigated. This was done by examining the expression of the sfiA-lac $Z$ fusion in microcin $\mathrm{B} 17$ producers and non-producers. Strain GC4415(pMM827) $\left(\mathrm{Mcc}^{-} \mathrm{Imm}^{+}\right.$) had 25 units of $\beta$-galactosidase throughout exponential growth, a value indistinguishable from that of the plasmid-less strain. In contrast, GC4415(pMM833) $\left(\mathrm{Mcc}^{+} \mathrm{Imm}^{+}\right)$had 50 units of $\beta$-galactosidase. Growth and viability of these 
strains were not significantly different. The twofold increase in sfiA-lac $Z$ expression was abolished when an shmA mutation (which confers resistance to microcin B17, M. Laviña, A. Pugsley \& F. Moreno, unpublished) was introduced into the producing strain (RYC359).

\section{DISCUSSION}

The results presented here and in the accompanying paper (Herrero \& Moreno, 1986) show that both sensitive and immune $E$. coli cells stop synthesizing DNA and induce several SOS functions when treated with microcin B17. For sensitive cells these effects were irreversible. In immune cells, these effects were reversible: treated bacteria were not killed, and eventually recovered the ability to synthesize DNA and resumed normal growth. Since an active replication fork is required for microcin induction of SOS functions and since inhibition of DNA synthesis after microcin treatment is immediate, we concluded that the primary effect of microcin B17 is to block the DNA elongation process (Herrero \& Moreno, 1986). No significant differences in the inhibition of DNA synthesis and in the induction of several SOS functions in sensitive and immune cells was detected. Therefore, the immunity mechanism does not affect the primary action of microcin, but rather must act after this event to block the later events which lead to bacterial death. Cell death is most likely to be due to the DNA degradation that follows inhibition of DNA synthesis. Massive release of nucleotides from chromosomal DNA of sensitive bacteria was observed $30 \mathrm{~min}$ after treatment with microcin, whereas no DNA degradation was detected in immune cells.

In immune cells the extent and duration of the inhibition of DNA synthesis and the efficiency of the microcin-induced SOS response depended on the copy number of the immunity gene(s). Cells recovered from the microcin treatment more quickly when more copies of the immunity genes were present. Indeed the extent of the observed effects and the time taken to recover depended on the relative ratio of microcin to immunity product(s). How does immunity prevent DNA degradation and how does it make the block in DNA replication reversible? All our results are consistent with the notion that immunity neutralizes or removes microcin from the replication fork after it has inhibited DNA synthesis, but before DNA degradation starts. This implies that the interaction between the microcin and the replication machinery does not produce structural damage to the DNA but only blocks DNA elongation. In sensitive cells the block would be irreversible and would somehow initiate DNA degradation and cell death. In immune cells the block would be reversed by removal of the microcin from its site of action by the immunity protein(s).

The level of stiA expression was twofold higher in microcin-producing strains than in strains carrying a $\mathrm{Mcc}^{-} \mathrm{Imm}^{+}$plasmid. This increase in the basal level of $s f i A$ expression was not observed in cells mutated in the $s b m A$ locus. These mutants are completely resistant to exogenous microcin. It follows that SOS expression above the basal level in cells producing microcin is due to microcin produced, excreted and then internalized by the cells. A corollary of this is that within microcin-producing cells the synthesis of the antibiotic and the molecule(s) conferring immunity are balanced to avoid the inhibiting effects of the antibiotic.

Colicinogenic bacteria are immune to the lethal effect of the colicin that they produce (Konisky, 1982). However, the immunity to cognate colicin is not absolute and genetically immune cells are sensitive to very high concentrations of colicin (Frederick, 1958; Mock \& Pugsley, 1982; Pugsley, 1984b). This phenomenon, known as immunity breakdown, has been analysed in detail only with colicin Ib. In this case, the biochemical effects which occurred during the immunity breakdown were similar to the effects found in sensitive cells exposed to low concentrations of colicin Ib (Levisohn et al., 1968). But, in contrast to what occurred with microcin, colicin Ib immune cells were killed by high colicin concentrations. This difference is probably a consequence of the different mode of action of these molecules. Inhibition of DNA synthesis does not have to be lethal, provided the block is eventually removed. However, the formation of ion-permeable channels in the membrane, the mode of action of colicin Ia and Ib (Konisky, 1982), will be lethal if immunity is not sufficient to prevent channel formation or function. The mechanism of immunity to microcin B17 seems to be a novel one in the sense that 
it does not neutralize the antibiotic agent before it reaches its site of action, but prevents the subsequent events that lead to cell death.

Microcin B17 is mutagenic in sensitive cells and this activity is rec $A$-dependent (Herrero \& Moreno, 1986). The $\operatorname{rec} A$ and $u m u C$ gene products are required for SOS-induced mutagenesis (Walker et al., 1982). These genes were efficiently induced in microcin-treated immune cells. Yet, microcin failed to increase the mutation frequency in $\mathrm{RecA}^{+} \mathrm{UmuC}^{+}$immune strains. This failure may be related to the lack of DNA degradation and killing in these strains and suggests that mutations in sensitive cells may be generated during the processing of pre-mutagenic lesions directly or indirectly caused by microcin. Most likely, this damage would be targeted around the replication forks blocked by the antibiotic.

The presence of wild-type alleles of $\operatorname{rec} B$ and $\operatorname{rec} C$ is required for SOS induction by treatments which block DNA elongation (Gudas \& Pardee, 1976; Oishi \& Smith, 1978; Oishi et al., 1978). The $\mathrm{RecBC}$ product is also required for microcin to induce the SOS system in immune cells, as well as in sensitive cells. However, it has to be pointed out that our results with microcin B17 immune cells are not consistent with hypotheses which propose that the endonuclease activity of the $\mathrm{RecBC}$ protein is responsible for generating the signal which switches on the SOS response (Irbe \& Oishi, 1980; Oishi \& Smith, 1978; Oishi et al., 1978). All the SOS genes and functions we tested were highly expressed, in spite of the fact that no DNA degradation could be detected in these cells. Similar results were obtained by Bockrath \& Hanawalt (1980) who investigated the $\mathrm{UV}$ induction of SOS in $u v r B \operatorname{rec} B$ mutants. It appears that, at least in these cases, another activity (not nuclease) of the RecBC product is required for RecA activation. On the basis of in vitro results, single-stranded DNA has been proposed to be part of the inducing signal in vivo (Roberts \& Devoret, 1983, Roberts et al., 1982). If RecA activation occurs when RecA protein binds to single-stranded DNA in the vicinity of the stalled replication fork, the role of the RecBC protein could be to facilitate this binding. Indeed, besides the nuclease activities of the RecBC protein, an unwinding and rewinding activity of this enzyme has been described (Taylor $\&$ Smith, 1980). This could be the activity required for SOS induction in the presence of microcin.

We are grateful to F. Baquero, A. P. Pugsley and M. Schwartz for useful discussions and to S. Jiménez and J. Talavera for technical assistance. This work was supported by grants from FIS (Ministerio de Sanidad) and ACS MV-168 (to R.K.). M. H. was the recipient of an FIS (Ministerio de Sanidad) predoctoral fellowship.

\section{REFERENCES}

BagG, A., Kenyon, C. J. \& Walker, G. C. (1981). Inducibility of a gene product required for UV and chemical mutagenesis in Escherichia coli. Proceedings of the National Academy of Sciences of the United States of America 78, 5749-5753.

Baquero, F. \& Moreno, F. (1984). The microcins. FEMS Microbiology Letters 23, 117-124.

Baquero, F., Bouanchaud, D., Martínez-Pérez, M. C. \& FERNÁNDEZ, C. (1978). Microcin plasmids: a group of extrachromosomal elements coding for low molecular weight antibiotics in Escherichia coli. Journal of Bacteriology 135, 342-347.

Bockrath, R. C. \& Hanawalt, P. C. (1980). Ultraviolet-light induction of rec $A$ protein in a $\operatorname{rec} B$ uirB mutant of Escherichia coli. Journal of Bacteriology 143, 1025-1028.

Casadaban, M. J. (1976). Transposition and fusion of the lac genes to selected promoters in Escherichia coli using bacteriophages lambda and Mu. Journal of Molecular Biology 104, 541-555.

Casaregola, S., DARI, R. \& Huisman, O. (1982). Quantitative evaluation of $\mathrm{rec} A$ gene expression in Escherichia coli. Molecular and General Genetics 185, 430-439.
Frederick, P. (1958). Colicins and colicinogenic factors. Symposia of the Society for Experimental Biology 12, 104-122.

Gudas, L. J. \& PardeE, A. B. (1976). DNA synthesis inhibition and the induction of protein $X$ in Escherichia coli. Journal of Molecular Biology 101 , 459-477.

Hernández-Chico, C., Herrero, M., Rejas, M., San Millán, J. L. \& Moreno, F. (1982). Gene ompR and the regulation of microcin 17 and colicin E2 syntheses. Journal of Bacteriology 152, 897-900.

Herrero, M. \& Moreno, F. (1986). Microcin B17 blocks DNA replication and induces the SOS system in Escherichia coli. Journal of General Microbiology' 132, 393-402.

Huisman, O. \& D'ARI, R. (1981). An inducible DNA replication-cell division coupling mechanism in $E$. coli. Nature, London 290, 797-799.

IRBE, R. M. \& OISHI, M. (1980). Prophage induction in a permeabilized cell system: induction by deoxyribonucleases and the role of the recBCdeoxyribonuclease. Journal of Bacteriology 144, 1061-1067. 
JAKES, K. (1982). The mechanism of action of colicin E2, colicin E3 and cloacin DF13. In The Molecular Action of Toxins and Viruses, pp. 131-167. Edited by S. van Heyninger \& P. Cohen. Amsterdam: Elsevier Biomedical Press.

KoNISKY, J. (1982). Colicins and other bacteriocins with established modes of action. Annual Review of Microbiology 36, 123-142.

Levisohn, R., Konisky, J. \& Nomura, M. (1968). Interaction of colicins with bacterial cells. IV Immunity breakdown studied with colicins Ia and Ib. Journal of Bacteriology 96, 811-821.

LitTle, J. W. \& Mount, D. W. (1982). The SOS regulatory system of Escherichia coli. Cell 29, 11-22.

Miller, J. H. (1972). Experiments in Molecular Genetics. Cold Spring Harbor, New York: Cold Spring Habor Laboratory.

Mock, M. \& Pugsley, A. P. (1982). The BtuB group Col plasmids and homology between the colicins they encode. Journal of Bacteriology 150, 1069-1076.

OISHI, M. \& SMITH, C. L. (1978). Inactivation of phage repressor in a permeable cell system: role of recBC DNAse in induction. Proceedings of the National Academy of Sciences of the United States of America 75, 3569-3573.

OISHI, M., SMith, C. L. \& Friefeld, B. (1978). Molecular events and molecules that lead to induction of prophage and SOS functions. Cold Spring Harbor Symposia on Quantitative Biology 43, 897907.

Pugsley, A. P. (1984a). The ins and outs of colicins. Part. I. Production and translocation across membranes. Microbiological Sciences 1, 168-175.

Pugsley, A. P. (1984b). Genetic analysis of ColN plasmid determinants for colicin production, release and immunity. Journal of Bacteriology 158, 523-529.

ROBERTS, J. \& DEVORET, R. (1983). Lysogenic induction. In Lambda II, pp. 123-144. Edited by R. W. Hendrix, J. W. Roberts, F. W. Stahl \& R. A Weisberg. Cold Spring Harbor, New York: Cold Spring Harbor Laboratory.
Roberts, J. W., Phizicky, E. M., Burbee, D. G., Roberts, C. W. \& Moreau, P. L. (1982). A brief consideration of the SOS inducing signal. Biochimie 64, 805-806

San Millán, J. L., Hernández-Chico, C., Pereda, P. \& MoRENO, F. (1985a). Cloning and mapping of the genetic determinants for microcin B 17 production and immunity. Journal of Bacteriology 163, 275-281.

San Millán, J. L., Kolter, R. \& Moreno, F. (1985b). Plasmid genes required for microcin $\mathrm{B} 17$ production. Journal of Bacteriology 163, 1016-1020.

Shinagawa, H., Kato, T., Ise, T., Makino, K. \& NAKATA, A. (1983). Cloning and characterization of the $u m u$ operon responsible for inducible mutagenesis in Escherichia coli. Gene 23, 167-174.

Sugino, A., Peebles, C. L., Kreuzer, N. K. \& Cozzarelli, N. R. (1977). Mechanism of action of nalidixic acid, purification of Escherichia coli nalA gene product and its relationship to DNA gyrase and a novel nicking-closing enzyme. Proceedings of the National Academy of Sciences of the United States of America 74, 4767-4771.

TAYLOR, A. \& SMITH, R. G. (1980). Unwinding and rewinding of DNA by the RecBC enzyme. Cell 22, 447-457.

W AlKer, G. C. (1984). Mutagenesis and inducible responses to deoxyribonucleic acid damage in Escherichia coli. Microbiological Reviews 48, 60-93.

Walker, G. C., Elledge, S. J., Kenyon, C. J., Krueger, J. H. \& Perry, K. L. (1982). Mutagenesis and other responses induced by DNA damage in Escherichia coli. Biochimie 64, 607-610.

Weaver, C. G., Redburg, A. H. \& Konisky, J. (1981). Plasmid mediated immunity of Escherichia coli $\mathrm{K}-12$ to colicin Ia is mediated by a plasmid-encoded membrane protein. Journal of Bacteriology 148, 817828.

WITKIN, E. M. (1976). Ultra-violet mutagenesis and inducible DNA repair in Escherichia coli. Bacteriological Reviews 40, 869-907. 